\title{
UJI KADAR ZAT WARNA ( $\beta$-karoten) PADA CABE MERAH (Capsicum annum. Linn) SEBAGAI PEWARNA ALAMI
}

\author{
Miftahus Saadah ${ }^{1}$, Nurdiana ${ }^{2}$, dan Dwi Wahyudiati ${ }^{3}$ \\ 1Jurusan Tadris IPA Biologi FITK IAIN Mataram \\ 2,3Dosen Tadris IPA Biologi FITK IAIN Mataram
}

\begin{abstract}
Abstrak
Penelitian ini berjudul uji kadar zat warna ( $\beta$-karoten) pada cabe merah sebagai pewarna alami yanag dilaksanakan mulai dari tanggal 14-15 Desember2015 di Laboratorium Kimia Analitik Fakultas MIPA Unram. Penelitian ini dilakukan untuk mengetahuikadar zat warna ( $\beta$-karoten) pada cabe merah sebagai pewarna alami. Cabai merah (Capsicum annuum Linn.) merupakan tanaman yang termasuk dalam keluarga Solanaceae.Berdasarkan penelitian yang telah dilakukan untuk mengetahui kadar $\beta$-karoten dalam cabe menggunakan satu jenis cabe, yaitu cabe merah, dan tiga sampel dengan berat yang berbeda-beda. Penelitian ini menggunakan metode spektrofotometer. Cabe segar yang telah dihaluskan diekstraksi dengan campuran aseton + n-heksana $(20 \mathrm{ml})$ metode maserasi. Setelah proses ekstraksi selesai ditambahkan aseton 9\% dalam heksana untuk pembuatan kurva standar. Penetapan kadar $\beta$-karoten dilakukan dengan metode spektrofotometer pada panjang gelombang $436 \mathrm{~nm}$. Hasil uji kualitatif menunjukkan bahwa dalam cabe merah besar (Capsicum annuum Linn.) teridentifikasi adanya $\beta$-karoten. Dari penelitian diperoleh hasil kadar rata-rata $\beta$-karoten pada masingmasing sampel I $(5,27)$, II $(5,52)$ dan III $(5,54)$. Dari hasil pengukuran menggunakan spektrofotometer dapat diketahui bahwa cabe merah banyak mengandung zat warna ( $\beta$-karoten). Berdasarkan standar warna yang ada, cabe merah termasuk penghasil $\beta$-karoten dengan kadar yang banyak sehingga bisa digunakan sebagai pewarna alami, akan tetapi pada makananmakanan terntu.
\end{abstract}

Kata kunci : Cabe Merah, $\beta$-karoten, Pewarna Alami 


\section{PENDAHULUAN}

Secara umum tumbuhan dapat diketahui pigmennya dengan menggunakan alat spektrofotometer.Spektofotometer mampu menangkap pigmen warna yang terkandung dalam tanaman dengan bantuan cahaya dan dengan panjang gelombang tertentu.Spektrofotometer merupakan alat yang prinsip kerjanya menggunakan absorsi cahaya.Panjang gelombang sangat berpengaruh dalam penentuan pigmen warna pada tanaman dengan alat spektrofotometer.Tumbuhan merupakan salah satu sumber daya alam penting, yang memiliki nilai khusus baik dari segi ekonomi.Tumbuhan merupakan tempat terjadinya sintesis senyawa organik yang kompleks menghasilkan sederet golongan senyawa dengan berbagai macam struktur. Usaha pencarian senyawa baru terhadap tumbuhan yang belum banyak diteliti akan lebih menarik danprospektif karena kemungkinan lebih besar menemukan senyawa baru.

Salah satu tumbuhan yang banyak memiliki sederet senyawa/ kandungan kimia seperti zat warna adalah cabai merah. Cabai merah (Capsicum annuum Linn) sering digunakan dalam masakan, selain itu tumbuhan ini juga menjadi sumber nutrisi yang penting bagi manusia terutama sebagai sumber vitamin A dan $\mathrm{C}$ dan senyawa-senyawa fenol asam dan netral. Buah cabai sangat banyak manfaatnya selain untuk kegiatan masakmemasak. Cabai yang kaya akan $\beta$ - karoten (vitamin A) dapat mencegah kebutaan kebutaan dan menyembuhkan sakit tenggorokan. Bidang industri memanfaatkan bubuk cabai dalam makanan dan minuman untuk menggantikan fungsi lada.

Penelitian menunjukkan bahwa cabai merah kaya vitamin $\mathrm{C}$ dan zat warna berupa $\beta$-karoten dengan kadar yang melebihi kandungan vitamin pada buah nanas, mangga, pepaya dan semangka. Untuk itu, penelitian bertujuan untuk menguji kadar zat warna ( $\beta$-karoten) pada cabe merah (Capsicum annum.Linn) sebagai pewarna alami. 


\section{METODE PENELITIAN}

Jenis penelitian yang digunakan pada penelitian ini adalah jenis Deskriptif Eksploratif, karena peneliti pada penelitian ini tidak melakukan perlakuan terhadap objek penelitian.Hanya saja peneliti disini menggambarkan keadaan yang ada pada objek penelitian tersebut.

Adapun pendekatan penelitian yang digunakan pada penelitian sesuai dengan objek yang akan diteliti adalah pendekatan kualitatif yang bersifat deskriptif karena pendekatan kualitatif merupakan penelitian yang bersifat atau memiliki karakteristik, bahwa datanya dinyatakan dalam keadaan yang sewajarnya atau sebagaimana adanya (Natural Setting) dengan langkah-langkah sebagai berikut.

\section{a. Ekstraksi $\beta$-karoten cabai merah (Capsicum annum.Linn)}

Ekstraksi $\beta$-karoten dari cabai merah (Capsicum annuum L.) dilakukan dengan metode maserasi. Digunakan metode maserasi karena senyawa $\beta$-karoten tidak stabil pada suhu tinggi sehingga warna pigmen akan berkurang pada pemanasan. Proses ekstraksi dilakukan dengan menggunakan variasi pelarut yaitu campuran aseton+ n-heksana.Waktu yang digunakan untuk maserasi adalah selama 10 menit dan pengocokan dengan shaker pada kecepatan $140 \mathrm{rpm}$. Pengocokan dilakukan untuk mempercepat kontak antara sampel dengan pelarut.Setelah itu dilakukan penyaringan, sehingga diperoleh filtrat ekstrak kasar berwarna orange.Warna orange memberikan gambaran bahwa pada ekstrak tersebut terdapat senyawa $\beta$-karoten, karena $\beta$-karoten merupakan suatu kelompok pigmen berwarna orange dan $\beta$ karoten terdapat pada buah yang berwarna merah. Ekstrak pekat aseton $+n$-heksana yang diperoleh diekstrak cair menggunakan corong pisah. Penambahan aquades menyebabkan terbentuknya dua fase yaitufase air (aseton: aquades) dan fase $n$-heksana. Fase n-heksana yang mengandung ekstrak kasar senyawa $\beta$-karoten diambil untuk pembuatan larutan standar baku. 


\section{b. Pengukuran Kadar Warna $\beta$-KarotenMenggunakan Spektropotometer UV}

Selanjutnya peneliti mengukur kadar $\beta$-karoten menggunakan alat spektrofotometer untuk mengetahui absorbansi dengan panjang gelombang serapan maksimum 436nm.

Penelitian ini dilaksanakan pada tanggal 14 Desember 2015 yang bertempat di Laboratorium Kimia Analitik Fakultas MIPA UNRAM.

\section{HASIL DAN PEMBAHASAN}

Hasil yang diperoleh dari proses ekstraksi beberapa sampel dapat dilihat pada Tabel 1 sebagai berikut :

\section{Tabel 1}

Berat dan Warna Ekstrak masing-masing sampel

\begin{tabular}{|c|c|c|}
\hline No sampel & Warna & Berat \\
\hline I & Orange muda & 5,38 \\
\hline II & Orange & 5,95 \\
\hline III & Orange tua & 6,16 \\
\hline
\end{tabular}

Pada Tabel di atas dapat dilihat bahwa ekstrak yang dihasilkan dari masing-masing sampel memiliki warna dan berat yang berbeda.Perbedaan warna ekstrak dari masing-masing sampel dikarenakan berat dari ke-tiga sampel yang berbedabedea.Semakin berat sampel yang digunakan maka semakin banyak kandungan $\beta$-karoten yang terdapat di dalam cabe.

Selanjutnya hasil pengukuran kurva baku disajikan pada tabel 2 berikut: 
MIFTAHUS SAADAH, DKK.

Tabel 2

Serapan larutan $\beta$-karoten Standar Pada BeberapaKonsentrasi

\begin{tabular}{|c|c|c|}
\hline No sampel & Konsentrasi & Absorbans \\
\hline I & 0,5 & 0,106 \\
\hline II & 2 & 0,217 \\
\hline III & 5 & 0,447 \\
\hline
\end{tabular}

Berdasarkan data-data pada Tabel 4.1 pada halaman 40 dan 4.2 pada halaman 40 diperoleh persamaan regresi linier yang menyatakan hubungan antara konsentrasi larutan $\beta$-karoten standar dengan serapan yaitu $Y=0,085 X+0,033$ dengan $r=0,995$, dimana $Y$ adalah serapan dan $X$ adalah konsentrasi dalam $\mu \mathrm{g} / \mathrm{mL}$. Setelah dibandingkan dengan koefisien korelasi (r) tabel $=0,959$ dengan taraf kepercayaan 99\% ternyatar hitung> $r$ tabel, yang menunjukkan bahwa adanya hubungan yang signifikan antara konsentrasi larutan $\beta$ - karoten standar dengan serapan sehingga dapat digunakan untuk penetapan kadar $\beta$-karoten dalam sampel. Hal ini dapat terlihat darigrafik kurva baku $\beta$-karoten standar yang berbentuk garis yang tidak lurus.

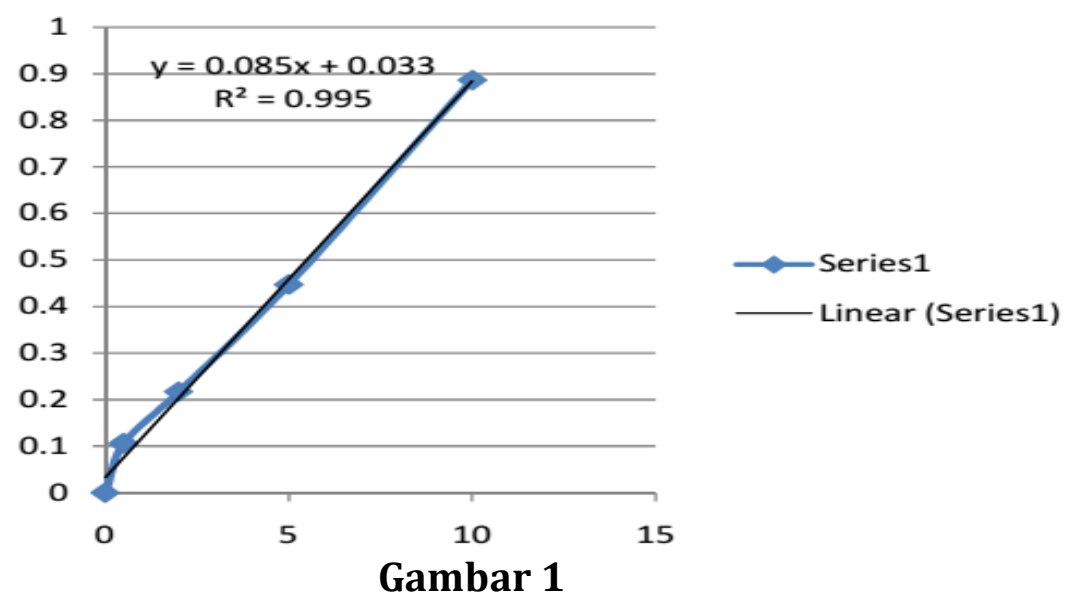

Hasil uji kualitatif, pembentukan warna dari Cabe merah besar (Capsicum annuum L.inn) dengan $\beta$-karoten standar 


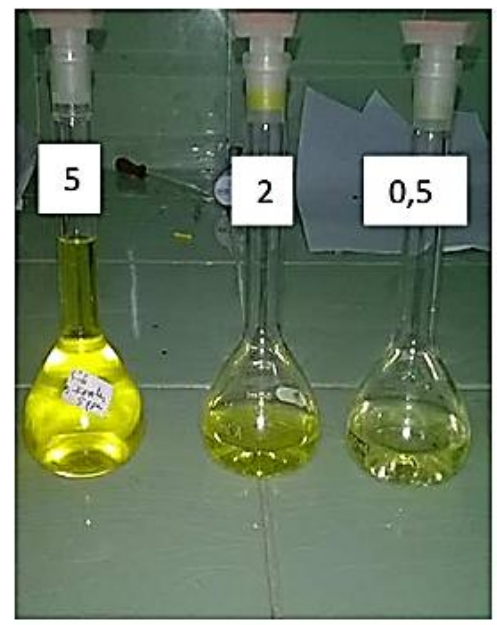

Standar $\beta$-karoten

Keterangan :

I $: 0,5=$ Orange muda

II $: 2$ = Orange

III $: 5$ = Orange tua

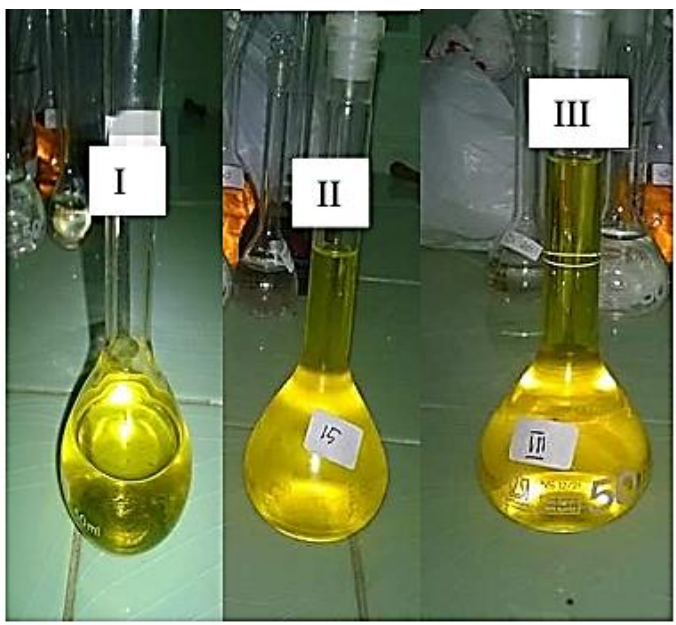

Pembentukan warna cabe merah

keterangan :

I : Orange muda

II : Orange

III : Orange tua

Bahan yang digunakan pada penelitian ini adalah cabe merah segar. Cabe merah merupakan tanaman yang kaya akan vitamin A. Cabe terkenal dengan warna merahnya yang cerah. Cabe merah dapat diketahui pigmennya dengan menggunakan alat spektrofotometer. Spektofotometer mampu menangkap pigmen warna yang terkandung dalam tanaman.

Diketahui bahwa pigmen $\beta$-karoten merupakan prekursor vitamin A. Sebagai prekursor vitamin A, $\beta$-karoten merupakan komponen dasar dalam makanan dan mempunyai peranan penting dalam kesehatan manusia. $\beta$-karotenmemiliki fungsi biologis yang sangat penting sebagai antioksidan, sistim imun, mencegah penyakit degeneratif, anti-inflamasi, anti stress (Johnson \& Schroeder, 1995). $\beta$-karotenjuga memiliki efek memperlambat penuaan (spot penuaan dan kerutan) dan menyembuhkan kelelahan otot, dapat melindungi kulit dari 
pengaruh buruk radiasi ultraviolet, dan meningkatkan sistim kekebalan tubuh.

Sebagian $\beta$-karoten adalah prekursor vitamin A. Satu molekul $\beta$-karoten yang dimakan dapat dirubah oleh enzim dalam usus halus menjadi dua molekul vitamin A. Saat ini suplemen vitamin A sering diberikan dalam bentuk $\beta$-karoten bukan sebagai vitamin A aktif. Hal ini karena konsumsi dalam $\beta$ karoten dalam jumlah banyak sampai saat ini diketahui tidak bersifat toksik, sedangkan konsumsi vitamin A aktif yang berlebihan dapat bersifat toksi. Pada penelitian ini menggunakan metode spektrofotometer untuk menentukan kadar $\beta$-karoten pada cabe merah.

Spektrofotometer merupakan alat yang digunakan untuk menganalisis konsentrasi suatu zat di dalam larutan berdasarkan absorbansi terhadap warna dari larutan pada panjang gelombang tertentu. Pada prinsipnya, sfektrofotometer bekerja apabila cahaya masuk dan jatuh ke medium, sebagaian cahaya masuk akan dipantulkan, sebagian diserap dan sebagian diteruskan. Cahaya yang diserap adalah nilai absorbansi. Hal ini sesuai dengan pernyataan Leph (2012) yang menyatakan bahwa prinsip kerja spektrofotometer adalah bila cahaya (monokromatik maupun campuran) jatuh pada suatu medium homogen, sebagian dari sinar masuk akan dipantulkan, sebagian diserap dalam medium itu, dan sisanya diteruskan.

Cabe merah yang sudah ditumbuk sebanyak 100 gram diekstrak menggunakan pelarut organik yang juga dapat melarutkan lemak.Aseton merupakan salah satu pelarut organik yang dapat melarutkan lemak dan pada praktikum ini digunakan aseton.Aseton mampu melarutkan pigmen dengan sempurna berbeda dengan air, walaupun dapat digunakan sebagai pelarut, namun air tidak mampu melarutkan pigmen dengan sempurna.Ekstraksi ini dilakukan untuk memisahkan komponenkomponen yangada dalam cabe merah yang bukan pigmen. $\beta$ karotentermasuk pigmennonpolar dan harus diekstrak dengan pelarut organik (aseton:n-heksana)dengan kepolaran tertentu. 
Pengenceran merupakan hal yang dilakukan sebelum sampel diukur menggunakan spektrofotometer. Pengenceran dilakukan untuk mengurangi kepekatan pada sampel dan agar mudah dibaca oleh spektrofotometer.Pelarut yang digunakan adalah aseton.Hal ini sesuai dengan pengenceran dilakukan untuk mengurangi kepekatan agar sampel dapat terbaca oleh alat absorbansi.Penentuan nilai absorbansi pada bahan praktikum, digunakan alat spektrofotometer.Dari hasil pengukuran, didapatkan bahwa absorbansi dari cabe merah pada sampel I sampel I $(0,516)$, II $(0,593)$, dan sampel III $(0,559)$. Warna yang dimiliki cabe merah pada saat uji spektrofotometer berkaitan dengan panjang gelombang cahaya tertentu yang diterima.Pada pengujian ini, warna cabe merah adalah warna orang dan dari hasil pengujian menggunakan spektrofotometer, panjang gelombang yang diterima adalah $436 \mathrm{~nm}$.Hal ini sesuai dengan peenelitian yang dilakukan oleh Lipi (1985) yang menyatakan bahwa panjang gelombang sinar tampak untuk warna warna orange berada dalam kisaran 610-750 nm.

Larutan standar merupakan salah satu bahan yang digunakan saat uji spektrofotometer.Pada praktikum ini, digunakan aquades.Larutan standar merupakan larutan yang konsentrasinya telah diketahui. Fungsi penggunaan larutan standar adalah untuk membuat kurva standar sehingga akan diperoleh panjang gelombang maksimum dari larutan standar tersebut. Larutan baku/ larutan standar adalah larutan yang konsentrasinya sudah diketahui. Larutan baku biasanya berfungsi sebagai titran sehingga ditempatkan buret, yang sekaligus berfungsi sebagai alat ukur volume larutan baku. Larutan yang akan ditentukan konsentrasinya atau kadarnya, diukur volumenya dengan menggunakan pipet volumetri dan ditempatkandi erlenmeyer.Berdasarkan pembahasan di atas dapat diketahui bahwabanyak sekali manfaat dari $\beta$-karoten. $\beta$-karotenmerupakan salah satu antioksidan yang dapat mencegah penyakit. Senyawa antioksidan ini mampu menetralisir zat-zat radikal bebas dalam tubuh yang merupakan sumber pemicu timbulnya berbagai penyakit terutama penyakit degeneratif. 
Secara alamiah $\beta$-karoten banyak terdapat pada buahbuahan seperti wortel, labu merah, buah merah, semangka, mangga, tomat, melon dan terdapat juga pada cabe.Salah satu cabe yang mengandung $\beta$-karoten adalah cabe besar.cabe dibedakan atas cabe merah, dan cabe hijau. Berdasarkan warnanya, maka kandungan $\beta$-karoten yang terdapat pada paprika juga berbedabeda (Astawan, 2008).

$\beta$-karotenyang terkandung didalam cabe merah juga digunakan sebagai pewarna alami pada makanan. Berdasarkan standar warna yang menjadi acuan pada laboratorium menunjukkan bahwa $\beta$-karoten pada cabe merah tergolong mengandung banyakkaroten. Dilihat dari hasil pengukuran menggunakan spektrofotometer dengan serapan sampel I $(0,516)$, II $(0,593)$, dan sampel III $(0,559)$ cabe merah termasuk kegolongan standar warna yang no 5 . Hal ini membuktikan bahwa antara ke-3 sampel dipengaruhi oleh berat sampel yang digunakan, semakin berat sampel yang digunakan maka semakin banyak kadar $\beta$-karoten yang dihasilkan. Selain itu, menurut standar warna $\beta$-karoten (sayuran) CI. No.75130 Kategori Pangan seperti Sup dan kaldu, Saus teremulsi (misalnya mayonais, salad dressing), Saus non-emulsi (misalnya kecap, saus tomat, saus keju, saus krim), $\beta$-karoten bisa digunakan sebagai pewarna alami pada makanan karena hasil penelitian $\beta$-karoten jauh dari batas maksimum standar warna yang sudah ditetapkan.

\section{PENUTUP}

\section{Kesimpulan}

Berdasarkan rumusan maslah, hasil penelitian, analisis data dan pembahasan, pada penelitian uji kandungan zat warna ( $\beta$ karoten) pada cabe merah sebagai pewarna alami ini dapat disimpulkan bahwa, kadar $\beta$-karoten yang terdapat pada cabe merah, yaitu 5,54. Dikaitkan dengan standar warna $\beta$ - karoten (sayuran) CI. No. 75130 batas maksimum penggunaan $\beta$-karoten pada makanan masih jauh dari batas yang telah ditetapkan sehingga bisa digunakan sebagai pewarna alami. Akan tetapi 
pewarna alami dari cabe merah tidak bisa digunakan pada semua makanan karena banyak mengandung capsaicin atau rasa pedas.

\section{DAFTAR PUSTAKA}

Anton Apriyanto, dkk, Analisis Pangan. Bogor : IPB, 1989.

Cahyadi, W, AnalissiS dan Aspek Kesehatan Bahan Tambahan Pangan Jilid 2.

Jakarta : Bumi Aksara, 2009. Dachlan Tosin dan Nurma Ratna sari. Sukses Usaha dan Budi Daya Cabai.Yogyakarta : Atma Media Press, 2011

De Man, J. M., Kimia Makanan, edisi kedua, ITB Bandung : Bandung, 1997. Emma S.Wirakusumah, Jus Sehat Buah \& Sayuran. Jakarta: Penebar Plus, 2013

Hadari Nawawi. Metode Penelitian dalam Teori dan Praktek, Jakarta: PT. RinekaCipta, 2004

Harborne, J.B. Metode Fitokimia Penuntun Cara Modern MenganalisisTumbuhan, Bandung: ITB, 2006

Harwimuka, Budi Daya Cabai Merah. Surabaya: Insan Cendekia, 2013.

Hidayat, Nur dan Anis Saati. Membuat Pewarna Alami. Surabaya: TrubusAgrisarana, 2006.

Husein Umar, Metode Penelitian untuk Skripsi dan Tesis, Jakarta: PT RajaGrafindo Persada, 2011.

Redaksi Agro Media, Panduan Lengkap Budi Daya dan Bisnis Cabai. Jakarta: Agro Media Pustaka, 2010.

Sugiyono.Metode Penelitian Pendidikan. Bandung: Alfabeta, 2012

Sugiyono.Metode Penelitian Kuantitatif, Kualitatif, Dan $R$ \&D.Bandung:Alfabeta, 2012

Suharsimi Arikunto, Metode Penelitian Pendidikan, Jakarta: Rineka Cipta, 2006

Setiadi, Bertanam Cabai. Jakarta: Penebar Swadaya, 1994

Setiadi, Bertanam Cabai di Lahan dan Pot. Jakarta: Penebar Swadaya, 2008. Setiadi, Bertanam Cabai di lahan dan Pot. Jakarta : Penebar Swadaya, 2012. 